Journal of Biotechnology and Strategic Health Research

Olgu Sunumu / Case Report

http://dergipark.org.tr/tr/pub/bshr

\title{
Yenidoğan Döneminde Dirençli Supraventriküler Taşikardi Olgusu
}

\author{
Resistant-Supraventricular Tachycardia in Neonatal Period
}

\section{Ayşegül Pala ${ }^{1}$, (D) Pınar Dervişoğlu Çavdaroğlu², (D) 凶 Öner Özdemir ${ }^{3}$}

\author{
${ }^{1}$ Çocuk Sağlığı ve Hast. ABD, Sakarya Üniversitesi Tip Fakültesi, Sakarya Üniversitesi Eğitim ve Araştırma Hastanesi, Sakarya \\ ${ }^{2}$ Çocuk Kardiyoloji, Sakarya Üniversitesi Tip Fakültesi, Sakarya Üniversitesi Eğitim ve Araştırma Hastanesi, Sakarya \\ ${ }^{3}$ Çocuk İmmünolojisi ve Alerji Hast. BD, Sakarya Üniversitesi Tip Fakültesi, Sakarya Üniversitesi Eğitim ve Araştırma Hastanesi, Sakarya \\ ORCID ID: Ayşegül Pala 0000-0001-9056-144X, Pınar Dervişoğlu Çavdaroğlu 0000-0001-5726-0362, Öner Özdemir 0000-0002-5338-9561 \\ *Sorumlu Yazar / Corresponding Author: Prof. Dr. Öner Özdemir, e-posta / e-mail: ozdemir_oner@hotmail.com \\ Geliş Tarihi / Received : 04-04-2020 Kabul Tarihi / Accepted: 20-04-2020 Yayın Tarihi / Online Published: 10-04-2020 \\ Atıf Gösterimi/How to Cite: Pala A., Dervişoğlu Çavdaroğlu P., Özdemir Ö. Yenidoğan Döneminde Dirençli Supraventriküler Taşikardi \\ Olgusu, J Biotechnol and Strategic Health Res. 2020;4(1):47-50
}

$\ddot{O} z$

Supraventriküler taşikardi (SVT) yenidoğan döneminde görülen en yaygın aritmidir. Kliniği asemptomatik seyirden kalp yetersizliği ve kardiyojenik şoka kadar değişkenlik gösterebilir. En sık görülen formu atriyoventriküler reentran tipi olmakla birlikte fokal atriyal taşikardi, nodal taşikardi, atriyal flutter ve fibrilasyon tipleri daha nadir olarak görülür. SVT prevalansı konjenital kalp hastası çocuklarda yaklaşık \%7'dir. Vagal manevralar, farmakolojik tedavi ve kardiyoversiyon ile çoğu vakada başarı sağlanır. Bazı kontrol altına alınamayan SVT olgularında aritmik durum hemodinamiyi bozar ve istenmeyen sonuçlara neden olabilir. Bu yazıda yenidoğan döneminde akut kalp yetersizliği ile başvuran, ancak tedavisinin 80 . saatinde aritminin kontrol altına alınabildiği dirençli SVT olgusu sunulmuştur.

Anahtar aritmi, supraventriküler taşikardi, yenidoğan, adenozin

Kelimeler

\begin{abstract}
Supraventricular tachycardia (SVT) is the most common form of arrhythmia in the neonates. The clinic presentation can vary asymptomatic course to heart failure and cardiogenic shock. Atrioventricular reentrant type is predominant mechanism while focal atrial tachycardia, nodal tachycardia, atrial flutter, and fibrillation types are more rarely seen. The prevalence of SVT is about 7\% in children with congenital heart disease. Vagal maneuvers, pharmacological therapy, and cardioversion successfully recover most cases. In some patients with resistant SVT, the arrhythmic condition deteriorates hemodynamic stability and may cause complications. In this case report, management of arrhythmia at the treatment of 80th hour in a neonatal patient with resistant SVT admitting with acute heart failure was presented.
\end{abstract}

Keywords arrhythmia, supraventricular tachycardia, neonate, adenosine 


\section{GIIRIŞ}

Yenidoğan supraventriküler taşikardi (SVT) yeni doğmuş çocuklarda en sık görülen aritmi olup prevalansı 25025.000 'de 1 olduğu tahmin edilmektedir. ${ }^{1}$ Yenidoğan döneminde SVT kendini genellikle huzursuzluk, taşikardi ve takipne ile gösterir. Çoğu SVT episodları aniden başlayıp kısa sürer ve kendiliğinden düzeldiği için tedavi gerektirmez. Genellikle 10-15 dakika süreli kısa episodlar halinde görülürken uzamış periyodlarda saatlerce sürebilir. Kliniği tablosu asemptomatik olabileceği gibi kalp yetersizliği ve kardiyojenik şoka kadar değişkenlik gösterebilir. ${ }^{2}$ En sık görülen formu atriyoventriküler reentran tipi olmakla birlikte fokal atriyal taşikardi, nodal taşikardi, atriyal flutter ve fibrilasyon tipleri daha nadir olarak görülür. Konjenital kalp hastalığı olan yenidoğanlarda SVT prevalansı yaklaşık \%7'dir. Vagal manevralar, farmakolojik tedavi ve kardiyoversiyon ile çoğu vakada başarı sağlanır. Bazı kontrol altına alınamayan SVT olgularında aritmik durum hemodinamiyi bozar ve istenmeyen sonuçlara neden olabilir. ${ }^{3}$ $\mathrm{Bu}$ çalışmada, yenidoğan döneminde akut kalp yetersizliği ile gelen en az 3 gün süren agresif tedavi sonrası aritmi tablosunun düzeldiği dirençli SVT olgusu sunulmuştur. Ayrıca yenidoğan SVT'lerinde her zaman tedaviye olumlu yanıt alınamayacağı, akut ve uzun dönem tedavisi ile ilgili net bir prosedür bulunmadığını ve her hasta için tedavinin bireysel olarak düzenlenmesi gerektiği anlatılmak istenmiştir.

\section{OLGU}

28 yaş annenin ilk gebeliğinden normal spontan vajinal yolla 3200 gr doğan erkek bebek postnatal 3. gününde emmede güçlük nedeni ile acile başvurdu. Fizik muayenesinde genel durumu bozuk, ciltte kutis marmoratus görünümü, yenidoğan refleksleri zayıf, solunum sayısı:60/dakika, kalp tepe atımı (KTA):258/dakika, kan basınc1: 80/50 mmHg, ateş: $36.7 \mathrm{oC}$ idi. Subkostal çekilmesi ve dinlemekle yaygın sibilan ralleri vardı. Karaciğer kot altı $3 \mathrm{~cm}$ ele gelen ve mezokardiyak odakta yaygın 3/6 pansistolik üfürümü mevcut olan hasta monitörize edildi. SVT ile uyumlu EKG'si (Resim 1) olduğundan antekubital damar yolu açılıp $0,1 \mathrm{mg} /$ $\mathrm{kg} / \mathrm{doz}$ adenozin yapıldı, yanıt alınamayınca $3 \mathrm{kez}$ ardışı artan dozlarda tekrar edildi. Yanit alınamayınca, sedasyon sonrası senkronize $1 \mathrm{j} / \mathrm{kg}$ kardiyoversiyon uygulandı. Yanıt alınamaması üzerine $2 \mathrm{j} / \mathrm{kg}$ kardiyoversiyon tekrar edildi ancak yine yanıt alınamadı. Amiodaron tedavisinin yanında akut kalp yetersizliği nedeni ile milrinon ve furosemid başlandı. KTA: 260/dk seyreden hastaya flekainid eklendi. Ancak kalp hızı kontrol altına alınamayınca Esmolol infüzyonu başlandı. Kombine antiaritmik tedavi ile yatışııın ancak 4. gününde ritim normale döndü. Ekokardiyografide ventriküler septal defekt, aort ark hipoplazisi ve patent ductus arteriosus saptandı. Kardiyak destek tedavisine bir süre daha devam edildi. Yatışının 10. gününde ayaktan tedavisi düzenlendi, çocuk kardiyoloji takibine alınarak taburcu edildi.

\section{TARTIȘMA}

Supraventriküler taşikardi (SVT) bebeklerde ve çocuklarda en sık görülen kardiyak aritmidir. Genelde zayıf beslenme ve taşipne gözlenirken tedavi edilmeyen durumlarda kalp yetmezliği ve kardiyojenik şok gelişebilir. SVT atağının tanısında öykü, fizik muayene ve EKG'den yararlanılır. Taşikardi muayenede anlaşılabilir ancak bazen septisemi veya pnömoniye sekonder gelişen sinüs taşikardisi ile karıştırılabilir. ${ }^{4}$ Hastamızın muayenesinde beslenmesi zayıf, huzursuz, cilt soluk idi. Hasta takipneik ve taşikardik idi.

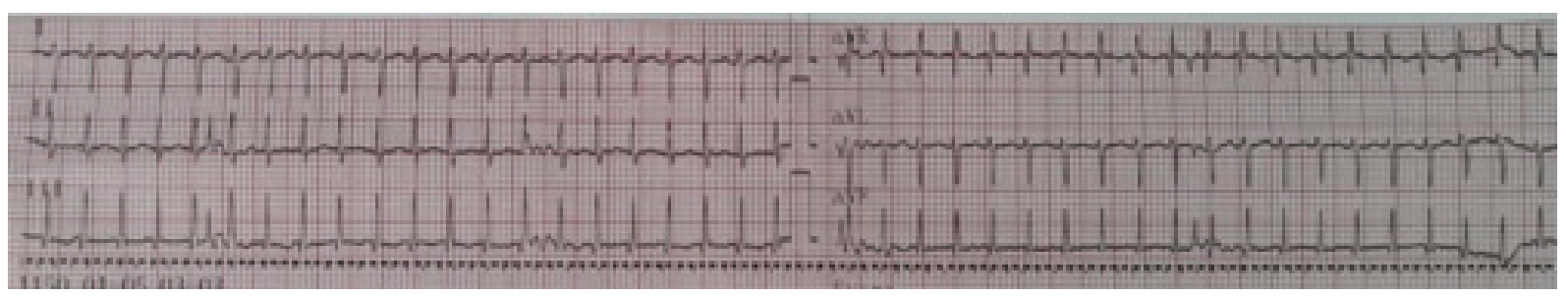

Resim 1: SVT uyumlu EKG 
Hastamızın kalp hızı 260/dakikaydı, EKG'de P dalgaları seçilmiyordu, düzenli, dar QRS taşikardi vardı. SVT atağı olarak değerlendirildi.

Adenozin, atriyoventriküler düğümün geçici bloğunu indükleyerek re-entrant yolağı kesen adenin nükleosittir. Yarı ömrü (10-15 saniye) oldukça kısa olup çoğu hastada atağı keser. Adenosin, SVT'li tüm hastalarda medikal tedavide ilk tercihtir. EKG ile adenosinin kalbe ulaşma etkisi izlenebilir. İlk doz $0.1 \mathrm{mg} / \mathrm{kg}$, tekrar doz $0.2 \mathrm{mg} / \mathrm{kg}$ ve maksimum dozu $0.3 \mathrm{mg} / \mathrm{kg}^{\prime} \mathrm{dir}^{5}$. Hastamızda sürekli tekrarlayan SVT episodlarından dolayı hastamıza başlangıç dozu $0.1 \mathrm{mg} / \mathrm{kg}$ 'dan başlayarak ardışık olarak 3 katına kadar çıkılarak adenozin tedavisi verildi. Ancak atak durdurulamadı, adenozine cevapsız olarak değerlendirildi.

Hemodinaminin stabil olmadığı SVT’lerde başlangıç tedavinin 0,5-2 J/kg kardiyoversiyon olması önerilir. Hastamızda iki defa 1-2 J/kg kardiyoversiyon tedavisi uygulanıp sinüs ritmine dönmesi sağlandı. Ancak hasta tekrar SVT'ye girdiği için tedaviden sonuç alınamadı. Bunun üzerine tedaviye amiodaron ile başlanarak ardından flekainid ve esmolol eklenerek devam edildi. Kombine antiaritmik tedavi ile yatışının 4. gününde sinüs ritmine dönen hastaya bir süre daha devam kardiyak destek tedavisi verildi. Yatışının 10. gününde ayaktan tedavisi düzenlenerek taburcu edildi. Yenidoğan SVT’leri refrakter olabilmektedir. Tedavide acil yaklaşım önemli olup her hasta için bireysel olarak düzenlenir. Dirençli aritminin mortalite ve morbiditeye neden olabileceği unutulmamalı ve bu hastalar multidisipliner olarak takip edilmelidir. 
J Biotechnol and Strategic Health Res. 2020;4(1):47-50

PALA, ÇAVDAROĞLU, ÖZDEMİR, Yenidoğanda Supraventriküler Taşikardi

Kaynaklar

1. Ludomirsky A, Garson A Jr. Supraventricular tachycardia. In: Gillette PC, Garson, A Jr, (eds.). Pediatric Arrhythmias: Electrophysiology and Pacing. WB Saunders, Philadelphia, PA, 1990: 380 .

2. Perry JC. Supraventricular tachycardia. In: Garson A Jr, Bricker JT, Fisher DJ, Neish SR, (eds.). Science and Practice of Pediatric Cardiology, 2nd edn. Williams and Wilkins, Baltimore, $M D, 1998: 2059$.

3. Jaeggi ET, Gilljam T, Bauersfeld U, Chiu C, Gow R. Electrocardiographic differentiation of typical atrioventricular node reentrant tachycardia from atrioventricular reciprocating tachycardia mediated by concealed accessory pathway in children. Am J Cardiol. 2003;91(9):1084-9.
4. Dadi G, Fink D, Weiser G. High-dose adenosine for refractory supraventricular tachycardia: a case report and literature review. Cardiol Young. 2017;27(5):981-984

5. Park M, Part 6: Arrytmias and Atrioventricular conduction Disturbances in Park's Pediatric Cardiology for Practitioners, 6e, Elsevier, India, 2014. 